\title{
Avaliação de Satisfação do Usuário como ferramenta para a Implantação de Melhorias no Cuidado ao Paciente Atendido em Hospital Especializado no Tratamento da Dependência Química.
}

Sabrina Verjas de Almeida, Lucas Cese Marchetti, Fabiana dos Santos, Audrey Navarro e Elizabeth Akemi Nishio

INTRODUÇÃO: Os transtornos desencadeados pelo uso de substâncias psicoativas atingem milhares de pessoas e atualmente contamos com vários dispositivos para tratamento destes pacientes, entre eles estão os hospitais especializados. Infelizmente poucos serviços falam sobre a satisfação do usuário, bem como a qualidade do atendimento. Há uma clara dificuldade dos serviços em escutarem os pacientes portadores de transtornos psiquiátricos (Wetzel, 2004). Uma das ferramentas utilizadas pela nossa instituição para a avaliação da qualidade da assistência é o Serviço de Atendimento ao Usuário. Acreditamos que avaliar a satisfação do usuário, contribui para a melhoria contínua e humaniza de forma expressiva 0 atendimento.

OBJETIVO: Relatar a experiência de melhoria na assistência, após a implantação do SAU - Serviço de Atendimento ao Usuário em hospital especializado no tratamento de dependentes químicos.

\section{MÉTODO : Relato de Experiência}

RESULTADOS E DISCUSSÃO: Há um ano foi implantado o Serviço de Atendimento ao Usuário no hospital com o objetivo de monitorar a satisfação do usuário e criar um canal de comunicação entre o paciente e a direção do hospital. As queixas e pesquisas de satisfação são realizadas diariamente, proporcionando ampla oportunidade ao paciente em expor suas dificuldades, queixas e sugestões. A responsável pelo serviço foi treinada pela equipe técnica para facilitar a comunicação, uma vez que deve-se ter habilidade na abordagem com os pacientes psiquiátricos. A equipe diretiva do hospital recebe e trata as queixas diariamente, realiza reuniões mensais, possibilitando desta forma realizar diversas ações de melhorias, que resultaram ao longo do ano em aumento da aceitabilidade geral de $82 \%$ para $93 \%$ e diminuição de $70 \%$ no número de queixas, conforme evidenciado nos gráficos abaixo.
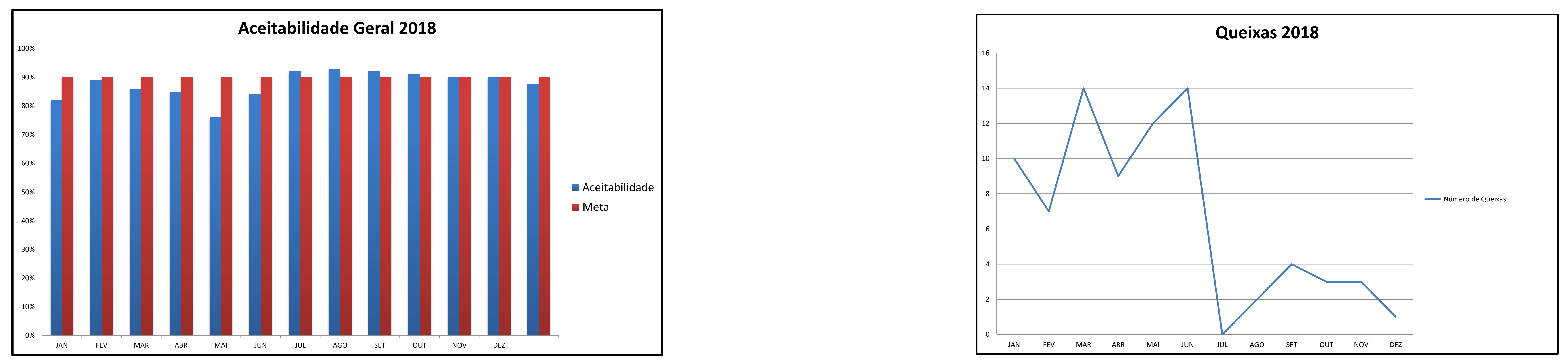

Dentre as principais queixas, estava o atendimento por parte da equipe de enfermagem. Como principal estratégia de melhoria, utilizamos a educação continuada e plano de ação conjunta diretamente com a equipe, inserindo todo o corpo de assistência de enfermagem nas queixas e resultados. Foram implementadas técnicas de manejo e comunicação terapêutica assertiva, melhoria na transferência de informações e os protocolos de contenção e manejo de crise. Outro ponto positivo foi a utilização de avaliação quantitativa por área para facilitar os resultados após as ações de melhorias.

CONCLUSÃO: Acreditamos que este é apenas o começo de um longo caminho que estamos percorrendo em busca da qualidade na assistência aos pacientes com transtornos psiquiátricos relacionados ao uso de substâncias, levando em conta 0 principal beneficiário, o paciente. É necessário que avancemos em ações de melhoria e qualidade cuja a métrica seja a necessidade do usuário. 